\title{
The impact of the pre-treatment interval on antimicrobial efficacy in a biological model
}

\author{
Andreas U. Gerber, Urs Greter, Charlotte Segessenmann and Stanislav Kozalk \\ Regionalspital Burgdorf and Department of Medicine, University of Bern, Switzerland
}

\begin{abstract}
The impact of pre-treatment intervals on the antipseudomonal efficacy of gentamicin, ticarcillin and ceftazidime was studied in an experimental thigh infection model in normal and granulocytopenic mice. Human-equivalent doses were used for simulating human pharmacokinetic profiles of the two study $\beta$-lactam drugs. A lethal inoculum of a virulent strain of Pseudomonas aeruginosa was injected into the thigh muscle. Treatment was started at various post-infection intervals. Antimicrobial efficacy was assessed by determinations of surviving organisms at the site of infection, and plasma drug concentrations were determined in the same mice. The age of infection had a substantisl impact on antipseudomonal efficacy of the three study drugs even though high, brief supra-MIC concentrations of gentamicin and persistent supra-MIC concentrations of the $\beta$-lactam drugs were obtained. A pre-treatment interval of six or more hours abolished the bactericidal effect of all three study drugs despite accumulation of the drugs to multiple-MBC plasma concentrations. We believe that the impact of pre-treatment intervals on antimicrobial efficacy is of paramount importance for the interpretation of antimicrobial activity studies in experimental models of infection, although the mechanisms remain to be elucidated.
\end{abstract}

\section{Introduction}

Many different factors are known to affect antimicrobial efficacy in vivo. Some of these factors, such as the infecting microorganisms, the site of infection and the intrinsic activity of an antimicrobial agent and its pharmacokinetic behaviour, have been well recognized and investigated in experimental models of infection (Drusano, 1991). On the other hand, the age of the infection (the pre-treatment interval) and the density of the infecting organisms have hardly been investigated, although their impact on overall success of an antimicrobial treatment can be assumed from clinical observation in such diseases as Gram-negative septicaemia in the granulocytopenic host (Hughes et al., 1990).

In the present experimental work the impact on the efficacy of three well-known antipseudomonal agents (gentamicin, ticarcillin and ceftazidime) against Pseudomonas aeruginosa of the pre-treatment interval and the number of bacteria at the site of infection were investigated. The experimental model was an artificial infection in the thighs of normal and granulocytopenic mice. After infection with a standardized inoculum, treatment in different groups of infected mice was started immediately or

Correspondence to: Dr Andreas U. Gerber, Division of Medicine, Regionalspital, CH-3400 Burgdorf, Switzerland. 
after a delay of $2,4,6$ or $8 \mathrm{~h}$. Dosage regimens of study drugs were chosen to give pharmacokinetic profiles similar to those seen in humans, where appropriate (Gerber $e t$ al., 1986; Gerber, 1991). Therapeutic efficacy was assessed by quantification of the number of bacteria at the site of infection over time and compared with plasma drug concentrations.

\section{Materials and methods}

\section{Bacterial strain}

All the main experiments were performed with $P$. aeruginosa A10, which was a clinical isolate obtained from Institute of Hygiene and Medical Microbiology, Bern, Switzerland.

\section{Media}

Trypticase Soy Agar TSA (BBL, Division of Becton, Dickinson \& Co., MD, USA) was used for the determinations of cfu. Plasma drug concentrations were determined on Diagnostic Sensitivity Test Agar (DST, Oxoid Ltd, Basingstoke, Hampshire, UK).

Drugs

All drugs were commercial products: gentamicin (Schering Corp., Kennilworth, NY); ticarcillin (Beecham AG, Bern, Switzerland); ceftazidime (Glaxo Group, Greenford, UK); cyclophosphamide (ASTA Werke AG, Bielefeld, Germany). The drugs were dissolved in distilled water according to the recommendations of the manufacturers. Further dilutions were made in physiological, pyrogen-free saline.

\section{Animals}

Female ICR-mice with a mean body weight of $28 \mathrm{~g}(27-31 \mathrm{~g})$ were obtained from Tierzuchtinstitut des Universitätsspitals der Universität Zürich, Switzerland.

\section{Production of leucopenia}

After an adaptation period of two days the mice were injected intraperitoneally with a first dose of cyclophosphamide (Endoxan), $150 \mathrm{mg} / \mathrm{kg}$ in $1 \mathrm{~mL}$ sterile saline. Two days later a second injection of $100 \mathrm{mg} / \mathrm{kg}$ in $1 \mathrm{~mL}$ saline was given. This treatment resulted in a severe leucopenia which lasted for at least four days (Gerber et al., 1982).

\section{Determination of plasma drug concentrations}

Plasma kinetics were determined in the same groups of mice that were used to study the drug's efficacy. Blood was drawn from the retro-orbital sinus of ether-anaesthetized mice into heparinized microcapillaries (Clay Adams, Dickinson \& Co). Plasma drug concentrations were determined the same day by a biological method (Sabath \& Anhalt, 1980). Bacillus subtilis ATCC 6633 was used as the indicator bacterium for determinations of gentamicin and ticarcillin concentrations, and Escherichia coli ATCC 25922 for ceftazidime. 


\section{Bacterial inocula and bacterial challenge}

Starting from several colonies of a pure culture of $P$. aeruginosa A10 a broth culture (Mueller-Hinton broth, supplemented with calcium and magnesium, as described by Stratton \& Reller, 1977) was inoculated and serially diluted. After overnight incubation at $37^{\circ} \mathrm{C}$ the culture was chosen that came closest to an optical density of 0.3 (read at $580 \mathrm{~nm}$ ), which corresponded to approximately $10^{8} \mathrm{cfu} / \mathrm{mL}$. The culture was centrifuged ( $2000 \mathrm{~g}$ for $10 \mathrm{~min}$ ), washed in physiological saline and resuspended to result in $10^{8} \mathrm{cfu} / \mathrm{mL}$. An inoculum of $0.1 \mathrm{~mL}$ was injected into one thigh of ether-anaesthetized mice. In each individual experiment the challenge inoculum was quantitated by cfu determinations.

\section{Quantification of cfu in the thigh of infected animals}

At various time intervals after bacterial challenge and after onset of treatment three to four mice were killed. The infected thigh was dissected and homogenized on ice in a Polytron tissue homogenizer (Kinematica, Luzern, Switzerland) in $4 \mathrm{~mL}$ ice-cold saline supplemented with $8.5 \mathrm{~g} / \mathrm{L} \mathrm{NaCl}, 50 \mathrm{mg} / \mathrm{L} \mathrm{Ca}^{++}, 20 \mathrm{mg} / \mathrm{L} \mathrm{Mg}^{++}$and $1 \mathrm{~mL} \beta$-lactamase (Watman Biochemicals, Maidstone, Kent, UK). Aliquots of serially diluted mouse-thigh homogenates were plated on agar plates and cfu counts were determined after incubation for 18-24 h.

\section{Antimicrobial chemotherapy and determinations of plasma pharmacokinetics}

All drug injections were made in aliquots of $0.1 \mathrm{~mL}$ subcutaneously. Treatment was started immediately after bacterial challenge $(0 \mathrm{~h})$ or $1,2,4,6,8$ or $10 \mathrm{~h}$ later. Gentamicin was given as a single, human-equivalent dose of $32 \mathrm{mg} / \mathrm{kg}$ (see Discussion for the definition of 'human-equivalent'). Ticarcillin and ceftazidime were given in fractionated decreasing doses such that a human-like pharmacokinetic profile could be obtained (Gerber et al., 1986, 1991; Gerber, 1991). Thus, the total dose of ticarcillin $(1000 \mathrm{mg} / \mathrm{kg})$ was given over $6 \mathrm{~h}$ in fractionated doses, every $15 \mathrm{~min}$, as follows: 225 , $120,3 \times 80,3 \times 52,3 \times 34,3 \times 22,3 \times 14,3 \times 9,3 \times 6$ and $4 \mathrm{mg} / \mathrm{kg}$. The total dose of ceftazidime $(250 \mathrm{mg} / \mathrm{kg})$ was injected in decreasing fractional doses every $20 \mathrm{~min}$ for a total of $8 \mathrm{~h}$ as follows: $56,25,30,3 \times 20,3 \times 13,3 \times 8.5,3 \times 5,3 \times 3.5,3 \times 2.25,3 \times 1.5$ and $1 \mathrm{mg} / \mathrm{kg}$. Untreated control mice were injected with equal total amounts of sterile saline.

\section{Results}

Antimicrobial susceptibility of P. aeruginosa $A 10$

In standardized diffusion tests $P$. aeruginosa A10 was susceptible to the three study drugs gentamicin, ticarcillin and ceftazidime. MICs (and MBCs) were $8(16) \mathrm{mg} / \mathrm{L}$ of gentamicin, $16(>256) \mathrm{mg} / \mathrm{L}$ of ticarcillin and $1(8) \mathrm{mg} / \mathrm{L}$ of ceftazidime.

\section{Growth of $\mathrm{P}$. aeruginosa $A 10$ in normal and granulocytopenic mice}

In comparative growth curves in normal and granulocytopenic mice, the clinical isolate of $P$. aeruginosa (A10) proved to be more virulent than the conventionally used laboratory strain ATCC 27853. The generation time of this bacterium in granulocyto- 


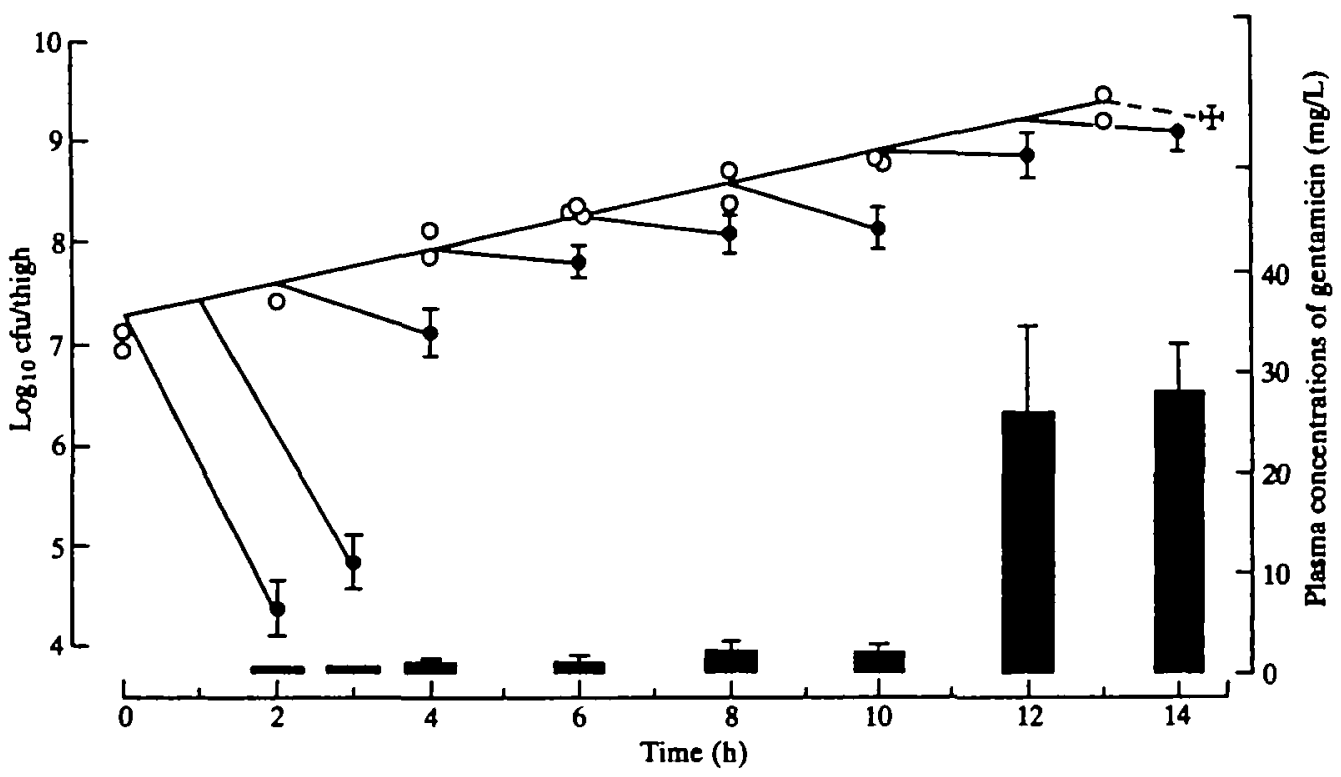

Figure 1. Bactericidal effect of a single dose of gentamicin $(32 \mathrm{mg} / \mathrm{kg})$ on $P$. aeruginasa $A 10$ in normal mice after various pre-treatment intervabs. O. Geometric mean of cfu/thigh \pm 1 so in four mice as obtained $2 \mathrm{~h}$ after the gentamicin injection; $O$. control saline injections; $\square$, mean gentamicin plasma concentration ( \pm l SD) $2 \mathrm{~h}$ after the gentamicin injection. The impact of the pre-treatment interval on bactericidal efficacy was highly significant and so was the gentamicin accumulation in mice after a pre-treatment interval of $>10 \mathrm{~h}$.

penic mice $(0.98 \mathrm{~h})$ was significantly shorter than that in normal, non-granulocytopenic mice $(1.86 \mathrm{~h})$.

\section{Pharmacokinetics of the study drugs in plasma}

In previous experiments the plasma half-life of gentamicin in mice was found to be $20 \mathrm{~min}$ (Gerber et al., 1986). In the experiments described below, this proved to be similar in freshly infected gentamicin-treated mice but not in septicaemic mice. For ticarcillin and ceftazidime a human-like pharmacokinetic profile was simulated, since in previous experiments these drugs had been shown to be poorly effective when given as a single bolus injection (Gerber, 1991; Gerber et al., 1991). By fractionation of the total dose of ticarcillin $(1000 \mathrm{mg} / \mathrm{kg}$ given over $6 \mathrm{~h})$, plasma peak concentrations of $185 \pm 28 \mathrm{mg} / \mathrm{L}$ and a plasma half-life of $88 \mathrm{~min}$ were obtained. This kinetic profile resulted in supra-MIC concentrations of ticarcillin for $P$. aeruginosa Alo for $6 \mathrm{~h}$. The human-adapted pharmacokinetic profile of ceftazidime showed a plasma peak concentration of $108 \pm 17 \mathrm{mg} / \mathrm{L}$ (after $20 \mathrm{~min}$ ) followed by a half-life of $131 \mathrm{~min}$. Supra-MIC concentrations of ceftazidime for $P$. aeruginosa Al0 persisted for a total of $8 \mathrm{~h}$. Thus, plasma peak concentrations and half-lives of the two $\beta$-lactam antibiotics corresponded to values usually seen in healthy human volunteers.

\section{Efficacy of gentamicin impact of the pre-treatment interval}

The impact of the pre-treatment interval on the efficacy of gentamicin is shown in Figures 1 and 2 for normal and granulocytopenic mice, respectively. In the thigh of 


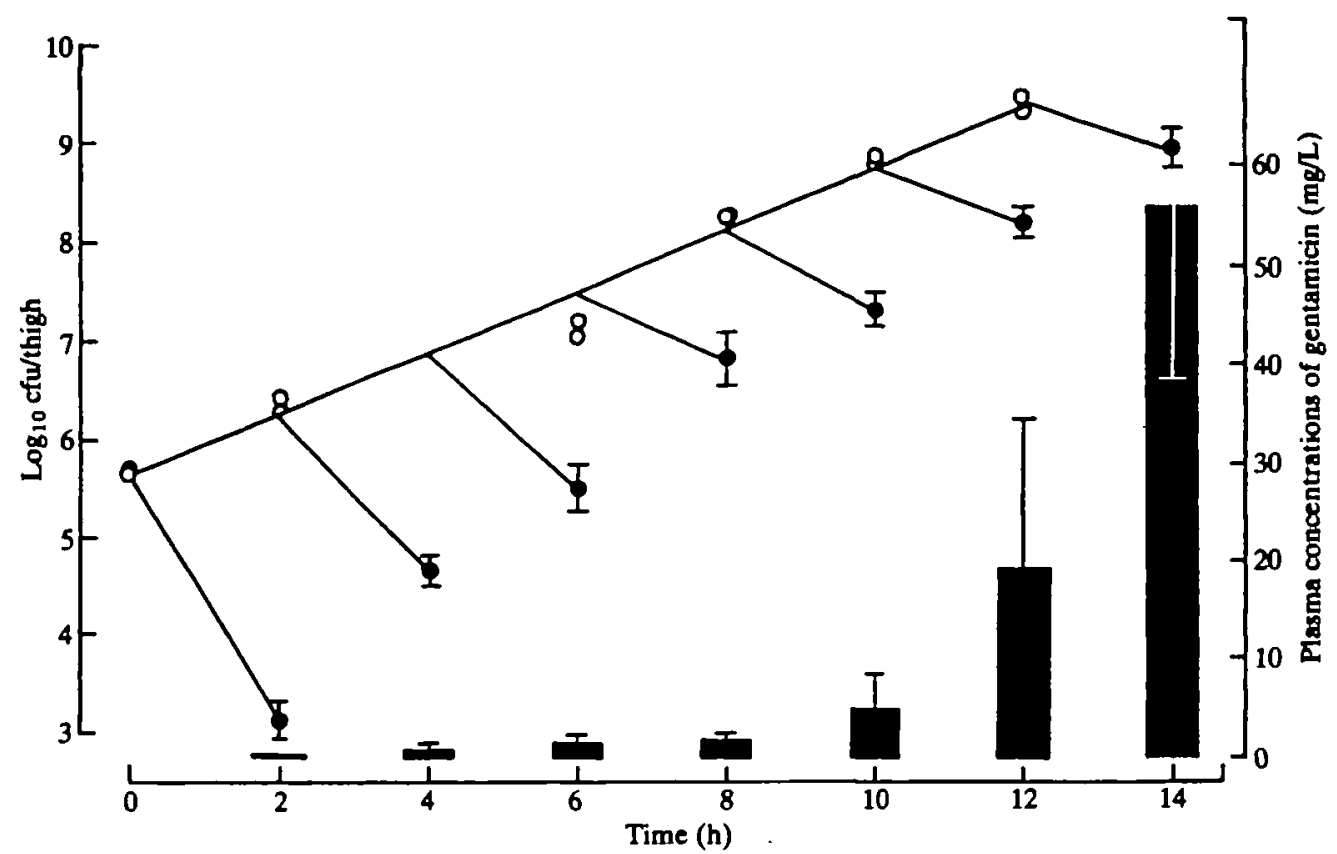

Figure 2. Impact of the pre-treatment interval on the antimicrobial efficacy of a single dose of gentamicin (32 $\mathrm{mg} / \mathrm{kg}$ ) on $P$. aeruginosa $\mathrm{A} 10$ in granulocytopenic mice. See Figure 1 for the key to the symbols.

untreated control mice pseudomonas grew log-linearly. In contrast, in normal mice, an initial inoculum of $10^{6}$ organisms replicated very unreliably (not shown), and for this reason experiments using non-granulocytopenic mice were started with an inoculum of $10^{7} \mathrm{cfu}$ per thigh. Thigh swelling occurred in normal and granulocytopenic mice approximately 3 to $4 \mathrm{~h}$ after bacterial challenge. Untreated, non-granulocytopenic control mice died within 14-24 h after bacterial challenge. In contrast, untreated granulocytopenic animals clearly had an overwhelming infection resulting in early septicaemia, shock and death within 14 to $16 \mathrm{~h}$.

When gentamicin treatment was started at the time of bacterial challenge, a pronounced bactericidal effect was obtained in normal and in granulocytopenic animals. More than $99 \%$ of the bacteria died within $2 \mathrm{~h}$. However, increasing the pretreatment interval resulted in a substantial reduction in bacterial killing. A pretreatment interval of more than $4 \mathrm{~h}$ in normal mice and more than $6 \mathrm{~h}$ in granulocytopenic mice almost completely abrogated the bactericidal effect. This abrogation of antimicrobial efficacy was most impressive when it was correlated with the plasma drug concentrations. In fact, probably owing to shock, the drug almost failed to be eliminated in the very ill animals. As a consequence of abolished drug elimination, plasma gentamicin concentrations of more than $20 \mathrm{mg} / \mathrm{L}$ persisted in animals with treatment onset later than $\mathbf{8}$ h after bacterial challenge. Paradoxically, such supra-MBC concentrations of gentamicin had a very poor antipseudomonal effect.

\section{Efficacy of ticarcillin: impact of the pre-treatment interval}

Experiments with ticarcillin were similar to those performed with gentamicin with the one exception that the drug was given in such a manner that a human-like pharmaco- 

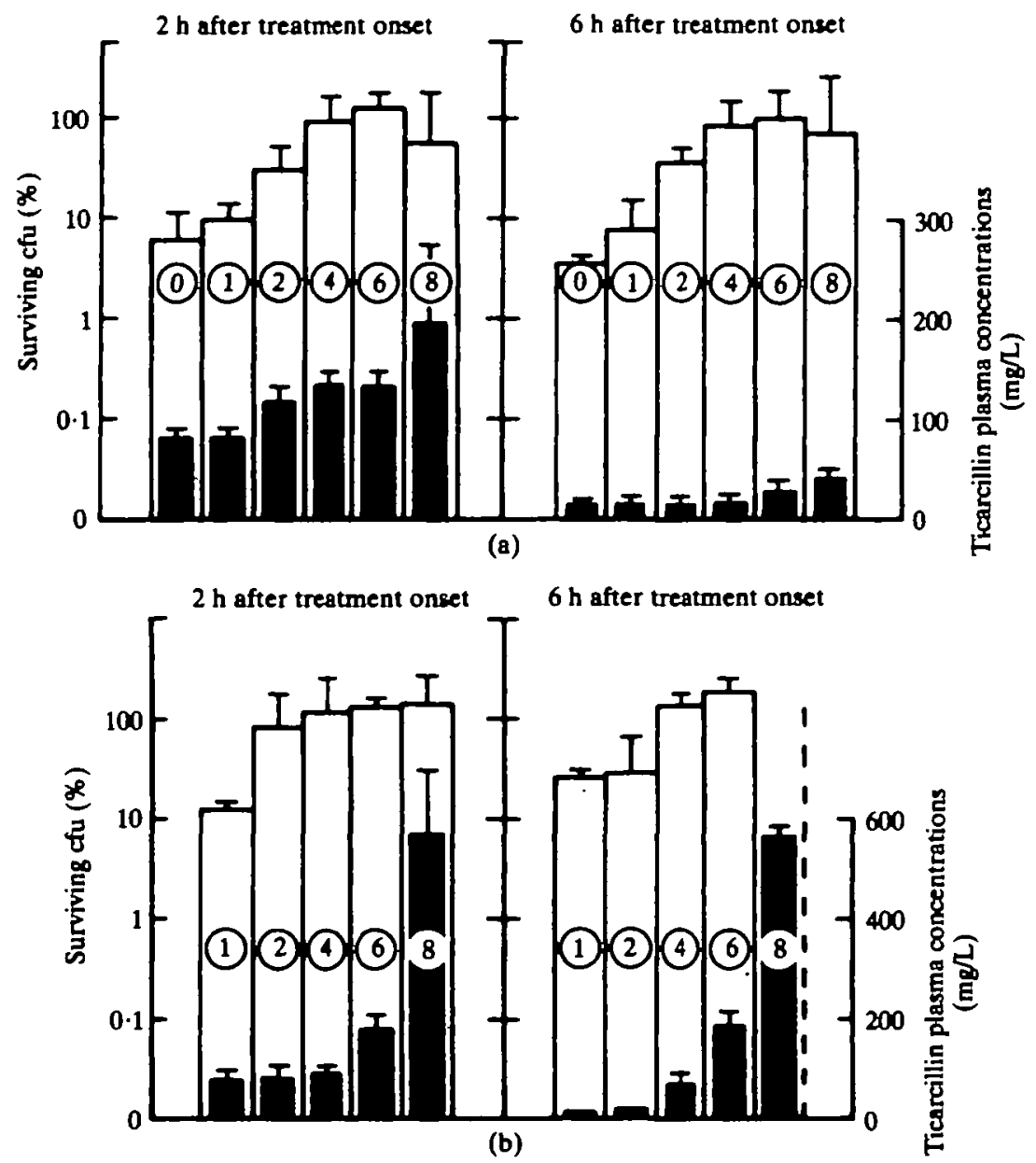

Frgure 3. Impact of the pre-treatment interval on antipseudomonal efficacy of a human-simulated single dose of ticarcillin in normal (a) and granulocytopenic (b) mice. $\square$, Surviving bacteria (\% of the pre-treatment ofu value per thigh $( \pm 1$ sD)). Circted numbers within the bars represent the pre-treatment interval $(\mathrm{h})$. The left panels represent the numbers surviving after $2 \mathrm{~h}$ of treatment; the right panels those surviving after $6 \mathrm{~h}$ of treatment. D. Ticarcillin plasma concentrations determined at $2 \mathrm{~h}$ (left panels) and $6 \mathrm{~h}$ (right panels). See text for comment.

kinetic profile was simulated. A bactericidal effect was observed after 2 or $6 \mathrm{~h}$ of treatment provided that ticarcillin had been started earlier than 2 to $4 \mathrm{~h}$ after bacterial challenge (Figure 3). In contrast, a merely bacteriostatic effect was obtained whenever the onset of ticarcillin treatment was further delayed. In both normal and granulocytopenic mice, the maximal antibacterial effect of ticarcillin treatment was obtained after $2 \mathrm{~h}$ despite the fact that supra-MIC ticarcillin plasma concentrations were maintained for four additional hours. Thus, a long pre-treatment interval clearly abrogated any bactericidal effect of ticarcillin.

Drug accumulation also proved to be dependent on the duration of the pre-treatment interval (Figure 3). Drug accumulation in granulocytopenic mice was significantly greater than in normal mice. As in gentamicin-treated mice, this phenomenon was probably due to persistent shock in granulocytopenic mice. However, despite the 


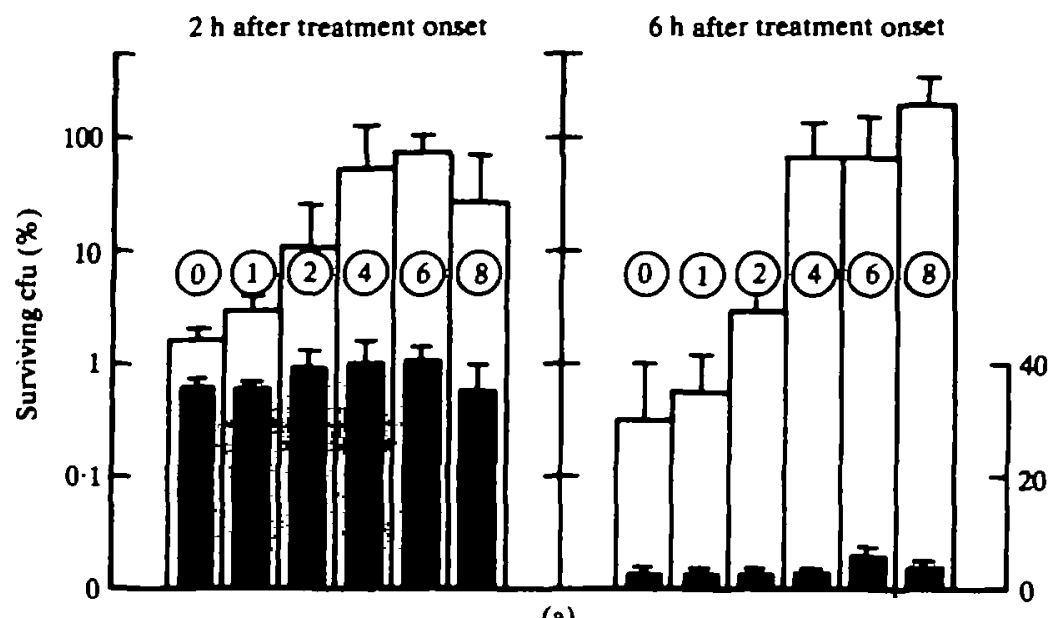

(a)

$2 \mathrm{~h}$ after treatment onset

$6 \mathrm{~h}$ after treatment onset

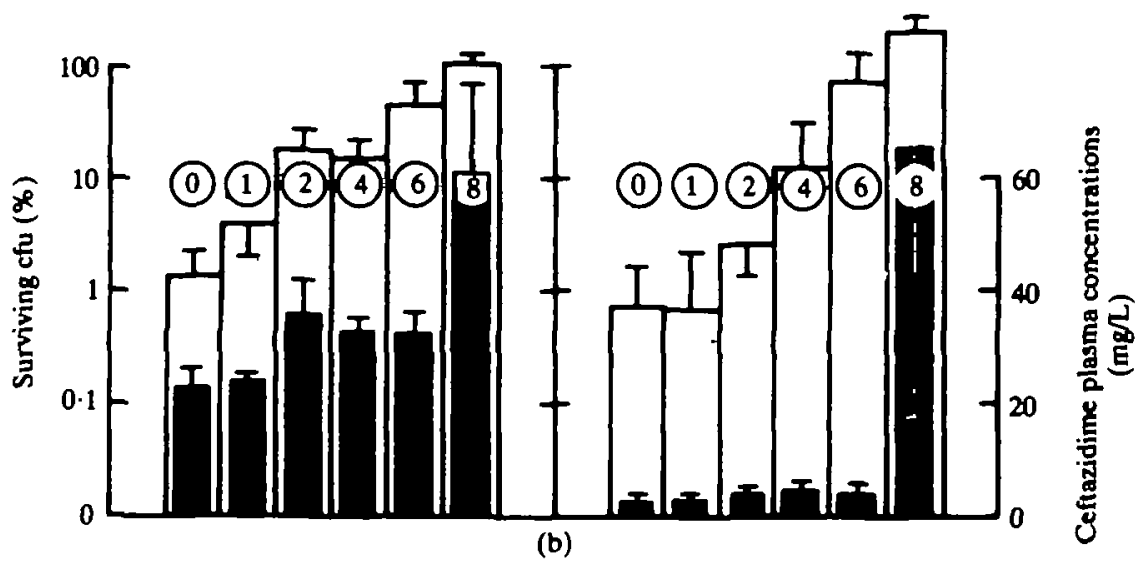

Figure 4. Impact of pre-treatment interval on the antibacterial efficacy of ceftazidime in normal (a) and granulocytopenic (b) mice. Effect $(\square)$ and drug concentration ( $(\square)$ as obtained with human-adapted dosing. Left and right panels show the results obtained 2 and $8 \mathrm{~h}$ after treatment onset, respectively. Circled numbers represent the pre-treatment interval (age of the infection) which had a significant impact on the efficacy of ceftazidime.

persisting supra-MIC drug levels in granulocytopenic (as opposed to normal) mice, antimicrobial efficacy was still poor. This was most evident in granulocytopenic animals with a pre-treatment interval of $8 \mathrm{~h}$. These animals all died despite a highly significant accumulation of ticarcillin (Figure 3(b)).

\section{Antibacterial efficacy of ceftazidime: impact of the pre-treatment interval}

Ceftazidime was the second $\beta$-lactam drug studied. Like ticarcillin, it was administered in fractionated doses such that a human-like pharmacokinetic profile was obtained. A total dose of $250 \mathrm{mg} / \mathrm{kg}$ of ceftazidime proved to be significantly bactericidal in normal as well as in granulocytopenic mice (Figure 4). Again, however, a highly significant correlation between the duration of pre-treatment interval and antimicrobial efficacy was found. If antimicrobial therapy with ceftazidime had not been started by 4 to $6 \mathrm{~h}$ 
after bacterial challenge, a merely bacteriostatic effect was seen during the $8 \mathrm{~h}$ treatment. When the onset of treatment in leucopenic mice was delayed for $8 \mathrm{~h}$ after bacterial challenge (i.e. when the bacteria had grown to $10^{3} \mathrm{cfu} / \mathrm{mL}$ ) no cidal effect whatsoever could be obtained despite the fact that the drug accumulated in these mice up to $60 \mathrm{mg} / \mathrm{L}$ (i.e. to 60 times and eight times the $\mathrm{MIC}$ and $\mathrm{MBC}$, respectively).

\section{Discussion}

Our investigations have clearly demonstrated the impact on antimicrobial efficacy of a period between bacterial challenge and onset of treatment with gentamicin, ticarcillin or ceftazidime. The impact of the pre-treatment interval (IPTI) correlated with the duration of this interval. The results of our study are in accord with the clinical truism that successful antimicrobial therapy varies with the severity of the bacterial infection. This clinical experience is most evident in granulocytopenic patients (Love, Schimpff \& Schiffer, 1980; Hughes et al., 1990).

Our studies were performed with a single treatment course of 6 to $8 \mathrm{~h}$ duration; drug doses were used which may look very high. It must be emphasized however, that (with the exception of gentamicin) drug levels in the plasma of the study animals reflected those normally seen under clinical conditions. By using the method of fractionating dosing we could approximate human pharmacokinetic profiles of the two $\beta$-lactam drugs. We have previously shown that the therapeutic effect of $\beta$-lactam antibiotics depends not only on the total amount of injected drug, but equally on the 'shape' of the area under the plasma concentration versus time-curve (Gerber et al., 1986, 1991; Gerber, 1991). In those experiments we had found in mice the human-equivalent dose and defined it as the amount of drug that was needed to simulate the human pharmacokinetic profile.

In the present study we did not simulate the human pharmacokinetic profile of gentamicin since earlier studies had shown that a single does of $32 \mathrm{mg} / \mathrm{kg}$ injected into mice corresponded to the human-equivalent dose, as this amount of drug was needed to simulate in a mouse the human pharmacokinetic profile. The shape of the AUC of gentamicin was not relevant to the efficacy of this particular drug (Gerber et al., 1986).

Our present study demonstrates that a pre-treatment interval can completely abolish the bactericidal effect of potentially bactericidal antibiotics. Moreover, if a very long pre-treatment interval was chosen, the animals became so severely ill that the study drug was not eliminated and hence accumulated to potentially toxic concentrations. Nevertheless, these extremely high drug concentrations proved to be less bactericidal than the very much lower drug concentrations seen after early treatment onset. Thus, for overall therapeutic efficacy the severity of the infection seems to be more important than the heights of attainable plasma levels or the overall AUC of the therapeutic agent.

Against Gram-positive cocci the impact on antimicrobial efficacy of both inoculum size and age of infection on experimental therapeutic efficacy has been known since the early days of penicillin (Eagle, 1949; Smith \& Wood, 1956). Pneumococci were easily eradicated with small doses of penicillin provided that penicillin treatment was started at the first day of infection and suppuration was absent (Smith \& Wood, 1956). The phenomenon was explained by the poor growth rate of the target bacteria in pus, but equally by the poor phagocytic activity of leucocytes in pus. More recently this phenomenon has been termed phenotypic tolerance and its mechanism has been partly 
elucidated (Tuomanen, 1986). Phenotypic tolerance in non-growing pneumococci was shown to correlate with the loss of autolysin molecules followed by a progressive change in the cell wall structure, which becomes less susceptible to autolysin-induced hydrolysis (Tuomanen \& Tomasz, 1991).

Against Gram-negative bacteria and $P$. aeruginosa in particular abrogation of antimicrobial activity by postponed treatment onset has previously been observed. As early as in 1956, Miles reported that streptomycin exerted a protective effect against $P$. aeruginosa infection only when treatment was started within $3 \mathrm{~h}$. He termed this 3-h interval the decisive period. More recently, Davey, Barza \& Stuart (1987, 1988), reported on antipseudomonal chemotherapy in experimental endophthalmitis and in the rat croton oil pouch model. Treatment with ciprofloxacin, gentamicin and imipenem was effective when started after $24 \mathrm{~h}$ of infection, but had little or no effect when delayed until $48 \mathrm{~h}$ after infection. Similarly, the pre-therapeutic duration of infection reduced the efficacy of ceftazidime and ciprofloxacin in Klebsiella pneumoniae pneumonia and septicaemia in leukopenic rats (Roosendaal et al., 1991).

Various factors might explain the effect of the pre-treatment interval on efficacy against Gram-negative bacteria. In previous studies (Davey et al., 1987, 1988) the relative bacterial resistance after delayed treatment onset was attributed to slower growth of the target organisms. This could definitely not be the decisive factor in our model, since treatment efficacy was diminished before the target bacteria came into a lag-phase. Thus, other factors must be involved. It is well known from in-vitro studies that a high density of $\beta$-lactamase producing bacteria diminishes the effect of $\beta$-lactam antibiotics (inoculum effect). The concentration of bacterial $\beta$-lactamases probably correlates with the density of the bacterial inoculum (Sabath et al., 1975; Eng, Smith \& Cherubin, 1984; Hall \& Opfer, 1984).

Another explanation of the inoculum effect could be that at very high bacterial densities bacterial clusters are formed through which the drug may hardly penetrate, so that the inner bacteria are protected. This mechanism of an inoculum effect may be of particular importance for $\beta$-lactam drugs such as ticarcillin and ceftazidime which predominantly bind to penicillin-binding protein 3 resulting in formation of bacterial filaments. Filaments are likely to be formed at the surface of bacterial clusters, and these may further hamper the penetration of the drug into the clusters (Gwynn, Webb \& Rolinson, 1981). Preliminary histological observations in our mouse thigh model revealed indeed very dense accumulations of bacteria and the formation of bacterial filaments in $\beta$-lactam treated animals.

Other mechanisms are likely to interfere with the activity of aminoglycosides. The biochemical environment at the site of infection could explain, at least in part, the effect of pre-treatment delay on the effectiveness of gentamicin in particular. The antimicrobial activity of aminoglycosides is greatly affected by a low $\mathrm{pH}$ and a low redox potential, i.e. factors known to be low at the site of infection (Hays \& Mandell, 1974; Verklin \& Mandell, 1977). Yet another mechanism could be some bacterial adaptation to the environment in vivo which in turn might lead to reduced susceptibility of the target organisms to various antimicrobial agents.

Finally, many different organisms and $P$. aeruginosa in particular produce an extracellular matrix which might well have a protective effect (Nickel et al., 1985). The production of this matrix is reversible and is hence probably due to genetic regulatory events or phenotypical changes (Bryan, 1989).

Our present work contributes to our understandings of the phenomenon of the pre- 
treatment interval-a factor of paramount importance for the study of antimicrobial activity in vivo.

\section{Acknowledgement}

This work was supported by the Swiss National Foundation for Scientific Research (grant 3.907-0.83).

\section{References}

Bryan, L. E. (1989). Two forms of antimicrobial resistance: bacterial persistence and positive function resistance. Journal of Antimicrobial Chemotherapy 23, 817-20.

Davey, P. G., Barza, M. \& Stuart, M. (1987). Dose response of experimental pseudomonas endophthalmitis to ciprofloxacin, gentamicin, and imipenem: evidence for resistance to 'late' treatment of infections. Journal of Infectious Diseases 155, 518-23.

Davey, P. G., Barza, M. \& Stuart, M. (1988). Tolerance of Pseudomonas aeruginosa to killing by ciprofloxacin, gentamicin and imipenem in vitro and in vivo. Journal of Antimicrobial Chemotherapy 21, 395-404.

Drusano, G. L. (1991). Human pharmacodynamics of $\beta$-lactams, aminoglycosides and their combinations. Scandinavian Journal of Infectious Diseases 74, Suppl., 235-48.

Eagle, H. (1949). The effect of the size of inoculum and the age of the infection and the curative dose of penicillin in experimental infections with streptococci, pneumococci, and Treponema pallidum. Journal of Experimental Medicine 90, 595-607.

Eng, R. H. K., Smith S. M. \& Cherubin, C. (1984). Inoculum effect of new $\beta$-lactam antibiotics on Pseudomonas aeruginosa. Antimicrobial Agents and Chemotherapy 26, 42-7.

Gerber, A. U. (1991). Impact of the antibiotic dosage schedule on efficacy in experimental soft tissue infections. Scandinavian Journal of Infectious Diseases 74, Suppl., 147-54.

Gerber, A. U., Brugger, H. P., Feller, C., Stritzko, T. \& Stalder, B. (1986). Antibiotic therapy of infections due to Pseudomonas aeruginosa in normal and granulocytopenic mice: Comparison of murine and human pharmacokinetics. Journal of Infectious Diseases 153, 90-7.

Gerber, A. U., Stritzko, T., Segessenmann, C. \& Stalder, B. (1991). Simulation of human pharmacokinetic profiles in mice, and impact on antimicrobial efficacy of netilmicin, ticarcillin and ceftazidime in the peritonitis-septicemia model. Scandinavian Journal of Infectious Diseases 74, Suppl., 195-203.

Gerber, A. U., Vastola, A. P., Brandel, J. \& Craig, W. A. (1982). Selection of aminoglycosideresistant variants of Pseudomonas aeruginosa in an in vivo model. Journal of Infectious Diseases 146, 691-7.

Gwynn, M. N., Webb, T. L. \& Rolinson, G. N. (1981). Regrowth of Pseudomonas aeruginosa and other bacteria after the bactericidal action of carbenicillin and other $\beta$-lactam antibiotics. Journal of Infectious Diseases 144, 263-9.

Hall, W. H. \& Opfer, B. J. (1984). Influence of inoculum size on comparative susceptibilities of penicillinase-positive and -negative Neisseria gonorrhoeae to 31 antimicrobial agents. Antimicrobial Agents and Chemotherapy 26, 192-5.

Hays, R. C. \& Mandell, G. L. (1974). pO2, pH, and redox potential of experimental abscesses. Proceedings of the Society of Experimental Biology and Medicine 147, 29-30.

Hughes, W. T., Armstrong, D., Bodey, G. P., Feld, R., Mandell, G. L., Meyers, J. D. et al. (1990). From the Infectious Diseases Society of America. Guidelines for the use of antimicrobial agents in neutropenic patients with unexplained fever. Journal of Infectious Diseases 161, 381-96.

Love, L. J., Schimpff, S. C., Schiffer, C. A. \& Wiernik, P. H. (1980). Improved prognosis for granulocytopenic patients with Gram-negative bacteremia. American Journal of Medicine 68, 643-7.

Miles, A. A. (1956). Nonspecific defense reactions in bacterial infections. Annals of the New York Academy of Science 66, 356-69. 
Nickel J. C., Ruseska, I., Wright, J. B. \& Costerton, J. W. (1985). Tobramycin resistance of Pseudomonas aeruginosa cells growing as a biofilm on urinary catheter materials. Antimicrobial Agents and Chemotherapy 27, 619-24.

Roosendaal, R., Bakker-Woudenberg, I. A. J. M., von den Berghe-van Raffe, M., Vink-van den Berg, J. C. \& Michel, M. F. (1991). Impact of the duration of infection on the activity of ceftazidime, gentamicin and ciprofloxacin in Klebsiella pneumoniae pneumonia and septicemia in leukopenic rats. European Journal of Clinical Microbiology and Infectious Diseases 10, 1019-25.

Sabath, L. D. \& Anhalt, J. P. (1980). Assay of antimicrobics. In Manual of Clinical Microbiology 3rd edn (Lennette, E. H., Balows, A., Hausler, W. J. \& Truant, J. P., Eds), pp. 485-90. American Society for Microbiology, Washington, DC.

Sabath, L. D., Gamer, C., Wilcox, C. \& Finland, M. (1975). Effect of inoculum and of $\beta$-lactamase on the anti-staphylococcal activity of thirteen penicillins and cephalosporins. Antimicrobial Agents and Chemotherapy 8, 344-49.

Smith, M. R. \& Wood, W. B. (1956). An experimental analysis of the curative action of penicillin in acute bacterial infections. Journal of Experimental Medicine 103, 509-21.

Stratton, C. W. \& Reller, L. B. (1977). Serum dilution test for bactericidal activity. I. Selection of physiologic diluent. Journal of Infectious Diseases 136, 187-95.

Tuomanen, E. (1986). Phenotypic tolerance: the search for $\beta$-lactam antibiotics that kill nongrowing bacteria. Reviews of Infectious Diseases 8, Suppl. 3, 279-91.

Tuomanen, E. \& Tomasz, A. (1991). Mechanism of phenotypic tolerance of nongrowing pneumococci to $\beta$-lactam antibiotics. Scandinavian Journal of Infectious Diseases Suppl. 74, 102-12.

Verklin, R. M. \& Mandell, G. L. (1977). Alteration of effectiveness of antibiotics by anaerobiosis. Journal of Laboratory and Clinical Medicine 89, 65-71. 